\title{
RECREATE THE ANCIENT URBAN LANDSCAPE. MULTIMEDIA AND INTERACTIVE TOOLS TO IMPROVE ACCESSIBILITY AND ENHANCEMENT OF THE ARCHAEOLOGICAL HERITAGE OF MILAN
}

\author{
A. Garzulino ${ }^{1}$, G. Zenoni ${ }^{2}$ \\ ${ }^{1}$ Dipartimento di Architettura e Studi Urbani (DAStU), Politecnico di Milano, Milano, Italy, andrea.garzulino@polimi.it \\ ${ }^{2}$ Independent researcher, gioia.zenoni@gmail.com
}

\section{Commission II}

KEY WORDS: Milan, archaeology, accessibility, enhancement, three-dimensional documentation

\begin{abstract}
:
The urban archaeological remains, especially in cities like Milan, have a number of issues closely related to the preservation and maintenance of the characteristics of each site, but today these issues appear to be equally fundamental and strictly linked to the awareness and accessibility of this hidden heritage. As part of the "Mediolanum MMXV" project, it was possible to investigate these topics by approaching areas with different characteristics and developing actions that allowed the full knowledge of the current state of these historical artefacts, highlighting the main critical aspects. The consequent activation of coordinated actions of knowledge, through a combination of three-dimensional documentation methodologies, activities of promotion and communication of the different archaeological sites in the central areas of Milan has led to the creation of a network structure aimed at creating the basis for a wider project able to increase its usability and valorisation thanks to multimedia communication and interactive virtual representation systems.
\end{abstract}

\section{INTRODUCTION}

"The identity of the Italian landscape is intimately connected to the special nature of an extended cultural heritage, widespread, dense, stratified and inscribed in the environment like few others in the world"1.

This statement - proposed in the ICOM Siena Charter - is so true if referring to the archaeological heritage of Milan, but how many people, thinking of it, would today consider the city a large open-air museum or a widespread museum?

The monuments of the ancient Mediolanum cover more than a millennium of history, spacing from the first Celtic settlement, to the Roman city that became a capital of the Roman Empire and a powerful Christian seat, keeping a strategic role also in the Gothic and Lombard occupation of Northern Italy (Fedeli, 2015).

The archaeological heritage includes the town wall, the forum, the theatre, the amphitheatre, the baths, many luxurious residences, the imperial palace and adjacent circus, the Bishop's complex and several remarkable Early Christian churches, that continued in use during the Early Medieval Epoch.

However, the remains of such splendid times suffered from a very dynamic building activity that invested the city over the centuries, so that nowadays they are very fragmented and lay hidden in the contemporary urban fabric (figure 1), often without the possibility of direct fruition ${ }^{2}$.

But if Mediolanum is still perceived as an "invisible city", the cause is primarily to be found in the scarce knowledge of its monuments by citizens and visitors and not only in the lack of visiting opportunities.

Upstream, one should point to inadequate communication strategies, unable to offer smart tools and a proper promotion

\footnotetext{
${ }^{1}$ Article 3 of the Siena Charter (ICOM Italia, 2014).

${ }^{2}$ For an overview of Milan's archaeological heritage and its conditions of protection, enhancement and enjoyment (Abbiati and Fedeli, 2014).
}

with respect to the special nature of the archaeological heritage of Milan.

On the contrary, this heritage is well represented in the archaeological literature and is constantly involved in high scientific dissemination, that should turn its aim also in reaching a wider audience and promoting citizens awareness, thus improving also the public sustain to the scientific research itself.

A reflection in this sense was carried out in the context of the large research project "Mediolanum MMXV" (competition announcement of the Regione Lombardia) conceived to gain the opportunity of Expo 2015 to enhance the archaeology of Milan through a multidisciplinary and experimental approach.

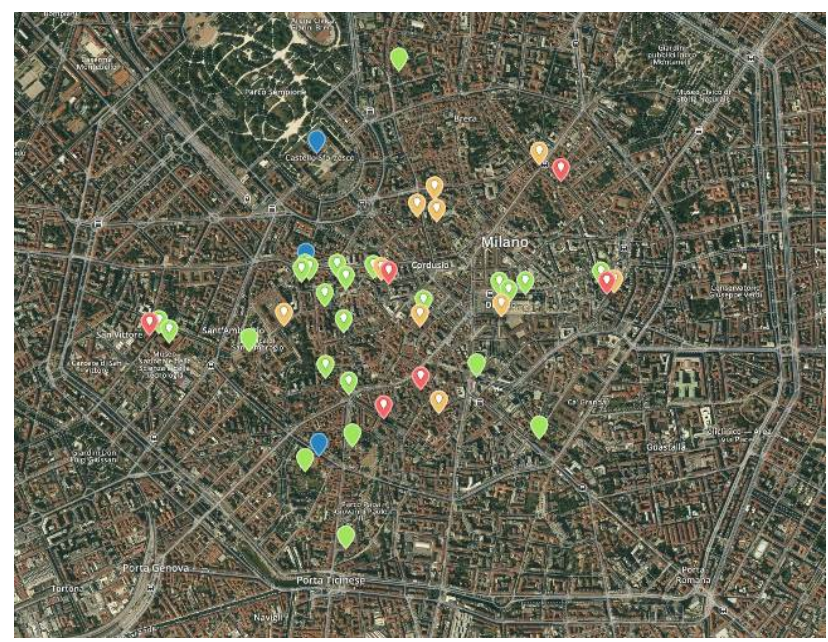

Figure 1. Location of the archaeological sites object of the Mediolanum MMXV project research. In green the accessible sites, in yellow the sites accessible on request, in red the sites not accessible to the public, in blue the main archaeological museums 
A network of four universities (Politecnico di Milano: prof. Paolo Gasparoli, prof. Susanna Bortolotto, Chiara Livraghi, Matteo Scaltritti, Fabiana Pianezze and Andrea Garzulino; Università Cattolica del Sacro Cuore di Milano: prof. Silvia Lusuardi Siena and Chiara Baratto; Università degli Studi di Milano: prof. Fabrizio Slavazzi and Daniela Massara; Libera Università di Lingue e Comunicazione IULM: prof. Luca Peyronel and Gioia Zenoni) was established to work together with the state, regional and municipal institutions (Soprintendenza Archeologia della Lombardia - now Soprintendenza Archeologia, Belle Arti e Paesaggio per la Città Metropolitana di Milano, Comune di Milano - Civico Museo Archeologico, Arcidiocesi di Milano) and the owners of the monuments involved in the research project, in order to deepen the knowledge of the archaeological sites, to study strategies for preventive conservation, restoration and accessibility, to develop new methods of communication and use.

\section{THE ACCESSIBILITY OF HERITAGE THROUGH MULTIMEDIA TOOLS: THE WEB PORTAL "MILANO ARCHEOLOGIA"}

The analysis of the critical issues related to the knowledge, accessibility and use of the archaeological sites in Milan highlighted the need for an integrated communication plan, for which IULM University was in charge, inspired by the methodological approaches of Public Archaeology (Skeates et al., 2012; Okamura and Matsuda, 2011; Bonacchi, 2009); and featuring the following specific aspects:

- invest in dissemination and care about the visualization of the heritage since the very beginning of an archaeological research project;

- develop multimedia tools and a language from time to time appropriate to the targets, avoiding a self-referential use of the new technologies (on new technologies at the service of cultural heritage: Bonacini, 2011, p. 11 and relative bibliography; noteworthy is also the critical discussion offered in Volpe and De Felice, 2014, pp. 213214);

- propose a unitary visual identity for the variegated and fragmented complex of the archaeological evidence through a coordinated image (Ferrara, 2007).

The latter is an essential condition for the reconstruction of a unitary picture of the landscape in its historical evolution. The remains dispersed in the urban fabric, in different states of conservation and with different accessibility conditions, are easily brought back to a single historical narration, only if their presentation is consistent. Standardizing the supports conveying the information related to them and the channels through which such information is accessible to the user is therefore a priority. Basing on such premises, the web portal "Milano Archeologia" was meant to be the main gate to quickly approach the ancient urban landscape through the many multimedia tools produced by the "Mediolanum MMXV" research team (figure 2).

The first portal entirely dedicated to Milan's archaeological heritage was created by ArcheoFrame IULM with the contribution of project partners and is hosted by the MiBAC server ${ }^{3}$.

The portal is designed to fulfill a dual purpose: on the one hand to systematically - but also synthetically - illustrate the

\footnotetext{
${ }^{3}$ The portal http://milanoarcheologia.beniculturali.it was designed and implemented by Gioia Zenoni with the computer and graphic support of Daniele Bursich, thanks to the coordination of Anna Maria Fedeli. The texts relating to archaeological sites are taken from Fedeli, 2015. For credits, see http://milanoarcheologia. beniculturali.it/?page id $=4619$
}

archaeological sites, relating places, finds and institutions and creating a network of existing dedicated resources, enhancing rather than replacing them (Filippi, 2004, pp. 57-59 sums up the web criteria for dealing with widespread cultural heritage); on the other hand, presenting the research in progress. This second theme allows to give a face to the research, illustrating the work of archaeologists and other professionals, and to impress greater immediacy to the diffusion processes.

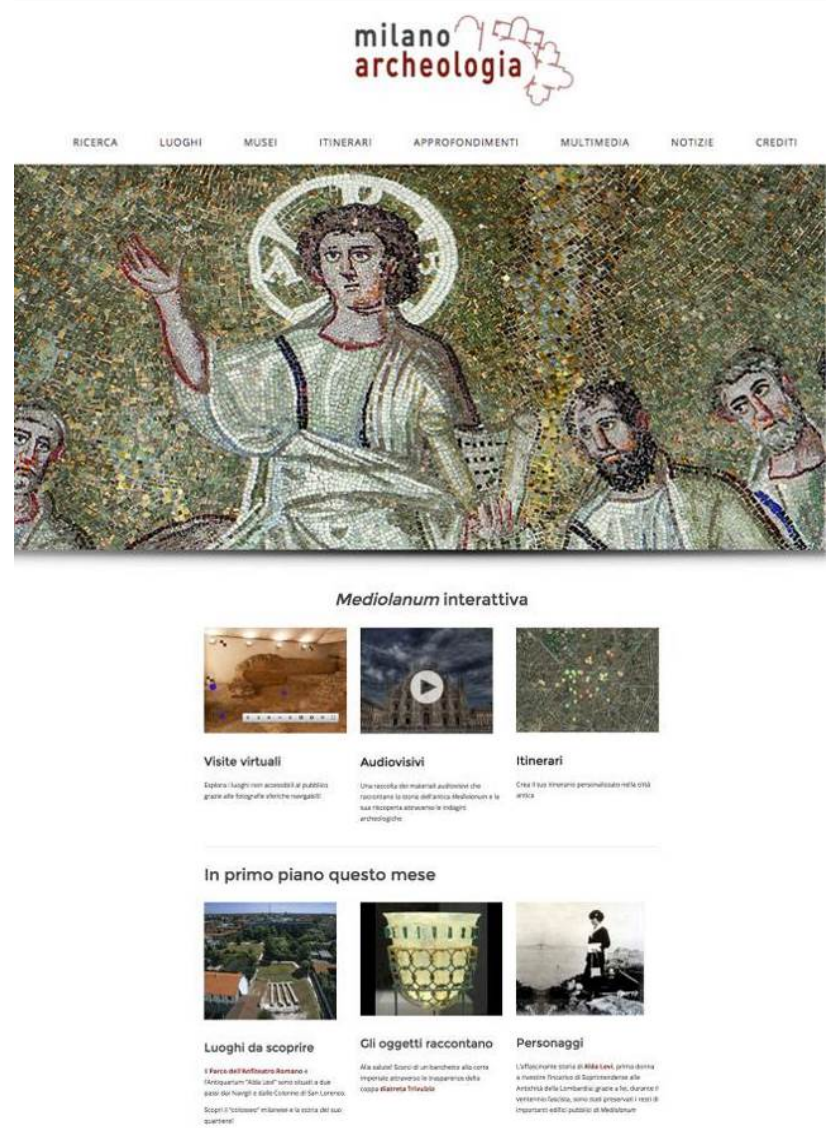

Figure 2. Home page of the "Milano Archeologia" web portal

The archaeological sites of Milan are proposed in the form of "rooms" of a widespread museum, or rather of an archaeological park (Fedeli et al., 2014, p. 206), and are interconnected on the basis of a chronological, temporal or thematic link or according to their belonging to the same architectural complex (figure 3). It is the case of the city wall, whose remains are scattered all around the city centre, often situated in private properties.

Every monument - or group of related remains - corresponds therefore to a web page containing a description, some visiting information, bibliographic references and external links to indepth studies or to additional multimedia such as mobile apps, a photographic gallery, plans, reconstruction sketches, videos and - whenever necessary - virtual tours.

The presence of information on how to use the sites fosters its attractiveness from the point of view of tourism, encouraged by the proposal of chronological and thematic itineraries that constitute a second option for browsing the content.

Multimedia and interactive tools must be intended not simply as forms of edutainment (Melotti, 2013, pp. 133-137), but above all as tools of knowledge at the service of the intangible accessibility of sites. Virtual tours through three-dimensional surveys made by Politecnico di Milano (figure 4) and video clips produced by ArcheoFrame IULM are aimed respectively 


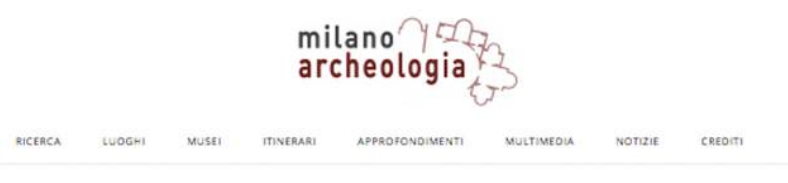

Le mura
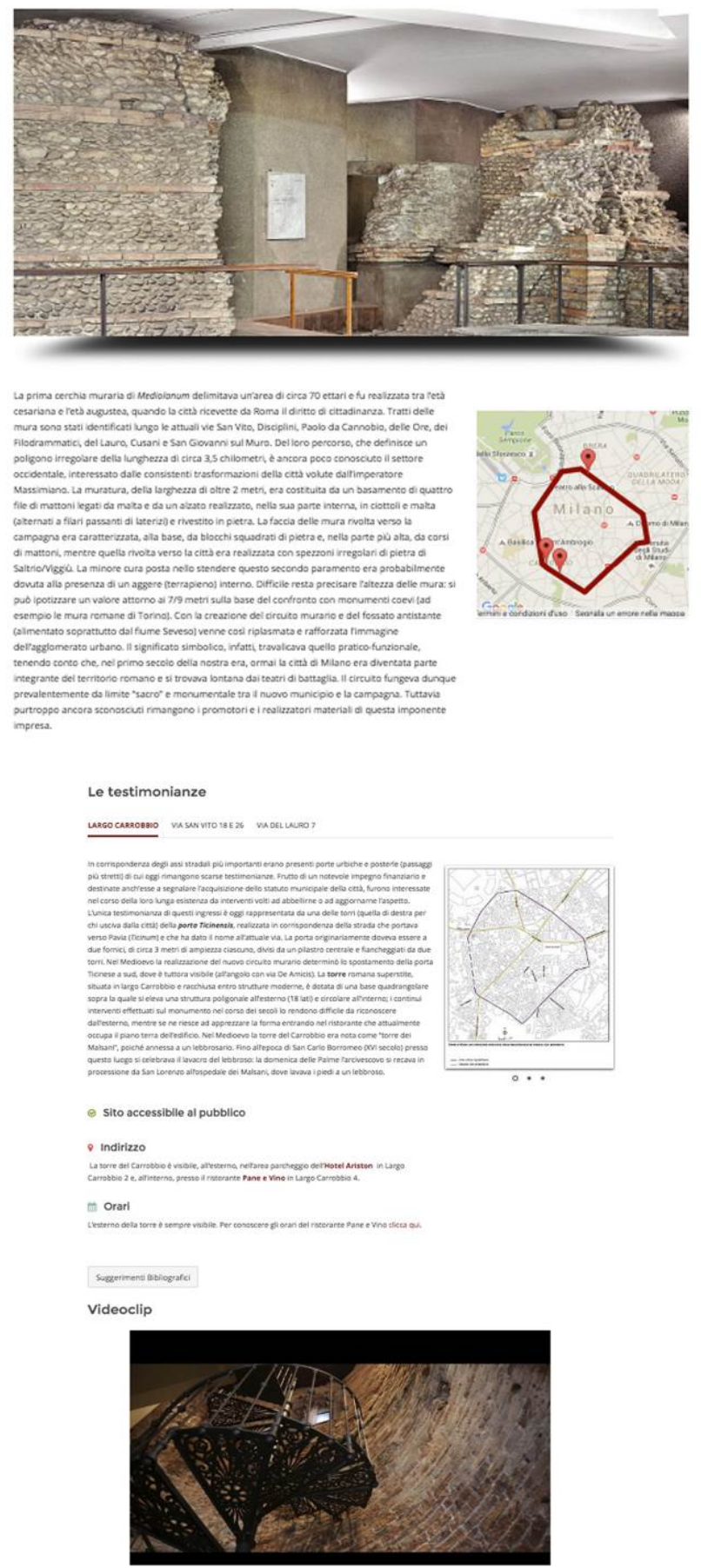

Figure 3. Example of the web page about the monumental complex of the "walls" in Milan

to make virtually accessible sites actually not open to the public and to return the suggestion of the spiritus loci through an emotional language, thus contributing to recompose the unity of the monumental complexes and to restore visibility, through multiple perspectives, to the landscape of the ancient city.

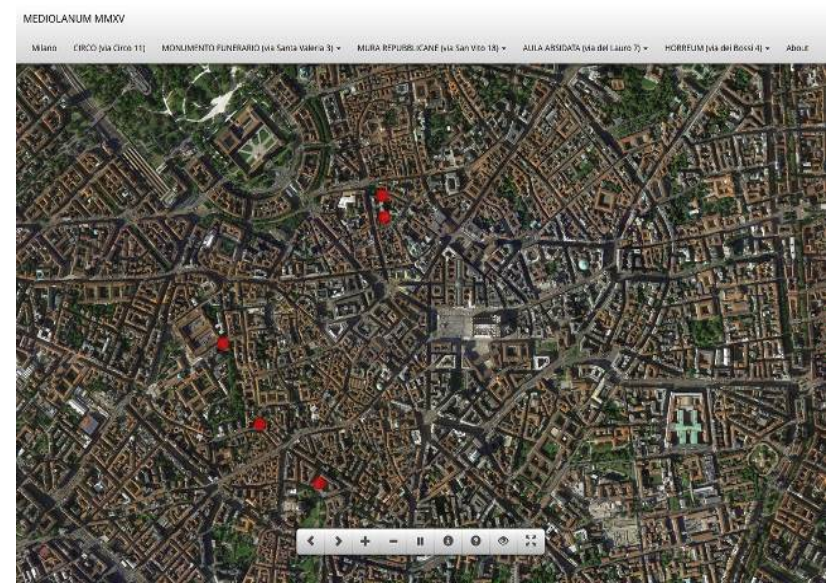

Figure 4. The graphical interface for virtual visits through navigable panoramic photos on the "Milano Archeologia" web portal

\section{THE INNOVATIVE DOCUMENTATION METHODOLOGIES AS A TOOL TO ENHANCE THE ARCHAEOLOGICAL SITES OF MILAN}

The city of Milan has a surprising archaeological heritage that has been preserved despite the development and urban transformations have fragmented the evidence, partially hidden the identity and denied the visibility.

These are objects that embrace a heterogeneous heritage: in fact, we pass from the large monumental buildings recognisable in the basilicas, to the archaeological remains preserved in the basements, almost completely erased from the subsequent edification, passing through some significant surviving evidences of public and private monuments, that can be found in the residual spaces of the modern city. Even today, this heritage is only partially open to visitors, resulting in little known and in a state of conservation that is not always such as to guarantee its survival and usability.

The research project "Mediolanum MMXV" continued along those lines of research that required further development and analysis with a view to enhance this heritage, through the implementation of its historical and morphological knowledge, ensuring a new use through digital documentation (Bartoli, 2002).

The research, reactivating the synergies already introduced for past projects, in particular has been able to integrate some gaps in the knowledge of the geometric and material consistency of some previously investigated sites, developing a methodological approach useful for recording data and for their subsequent processing phases (Gonizzi et al., 2012).

The initial part of the research saw the identification of the artefacts on which the activities were concentrated, selecting different structures, both from the point of view of typologies and materials, both from the point of view data and documentation collected from archives and libraries, in order to obtain a set of sites as differentiated as possible by characteristics and specificity, among which the most important:

- remains of Roman Circus, via Circo 11, Milan;

- remains of a Horreum, via dei Bossi 4, Milan;

- remains of Republican walls, via del Lauro 7, Milan;

- remains of an apsed space, via del Lauro 7, Milan; 
remains of "Massimianee" walls, via Montenapoleone 27, Milan;

remains of Republican walls, via San Vito 18, Milan; remains of Republican walls, via San Vito 26, Milan;

remains of structures and a sculptural apparatus at Santa Maria alla Fonte Church, Milan;

remains of the Funerary Monument, via Santa Valeria 3, Milan.

The planned activities are therefore aimed at obtaining quantitative databases (three-dimensional geometric data) and qualitative databases (photographic data), acquired and processed through different methodologies able to bring out the peculiarities of the archaeological structures for their knowledge, conservation and enhancement (Guidi et al., 2009).

\subsection{Data acquisition phase}

The first data recording activities have allowed to develop all the documentation methodologies as well as the most suitable acquisition instruments for each of the above-mentioned sites. During the first surveys, some of the data collection operations were simulated with different configuration parameters for each modality, in such a way as to precisely define which the best techniques were to apply to all the contexts. These inspections aimed to gather the most useful information to test and to calibrate available tools and methodologies, highlighting the potentials and the criticalities of each way of three-dimensional data acquisition.

Once this first knowledge phase was completed and after examining the morphological and dimensional aspect, the location of the affected portions, the lighting conditions and the results of the first acquisitions, we opted for a combined use of different acquisition methodologies:

acquisition, by total station, of topographic references for the creation of a network for the point clouds verification and alignment;

- acquisition, by laser scanner, of three-dimensional point clouds with a good overlap between the recordings for covering the entire area occupied by the archaeological remains, so as to fill the possible hidden areas due to the morphology of the remains and to increase the final density of the points;

acquisition of high-resolution photographic shots for the application of image based photogrammetric systems and structure from motion techniques with the aim of creating textured three-dimensional models;

- acquisition of sequential shots for the creation of high resolution interactive spherical images.

First, for each site, some topographic references have been positioned, useful for placing, aligning and recording successive clouds of points acquired through laser scanner technology (figure 5). The instrument used for three-dimensional documentation is a high-speed terrestrial laser scanner (FARO Focus 3D 120 Uni) that uses phase shift technology and equipped with an integrated digital camera with a 2 megapixel sensor. This tool is of limited size and weight, especially useful in complex situations such as those of archaeological sites and artefacts.

The targets have been placed on the walls of the spaces inside which the remains are kept, so as not to have portions of particular interest not adequately detected or covered during the laser and photographic shooting. The reference points were also placed at different heights, between $0.30 \mathrm{~m}$ and $3.50 \mathrm{~m}$ from the ground, at a distance not less than $0.50 \mathrm{~m}$ from the laser scanner and in such a way that the angle of incidence between the laser beam and the chessboard reference is not less than $35^{\circ}$, this to minimize the inaccuracies in the finalising operations of the point clouds.

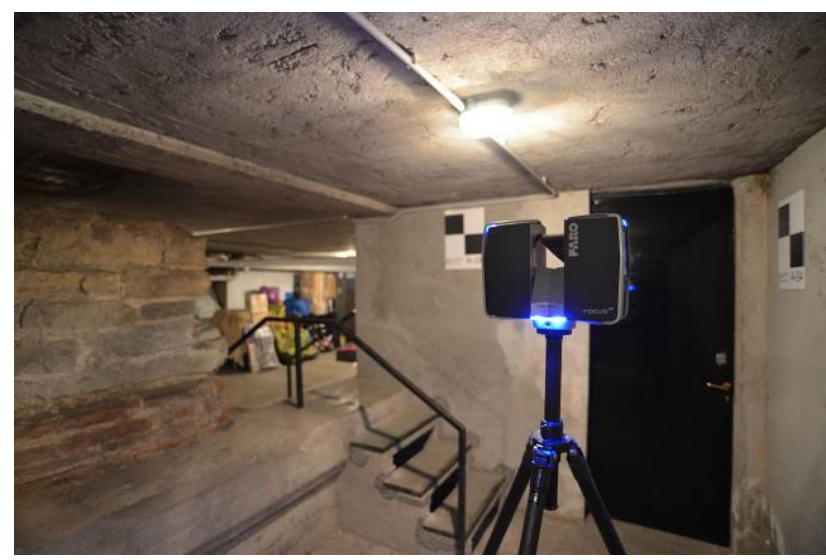

Figure 5. The scanning activities in via San Vito 18

Considering the location of the structures and their geometric, material and archaeological peculiarities, we proceeded by identifying different scanning points from which to perform the acquisitions, in order to obtain very detailed and high-quality restitutions from the point of view of both the geometries both the colours.

All the recordings were performed with a $360^{\circ}$ rotation around the vertical axis and $300^{\circ}$ around the horizontal axis, positioning the instrument at a height between $0.50 \mathrm{~m}$ and 1.80 $\mathrm{m}$ from the ground. On the other hand, the resolution parameters have been modified according to the characteristics of the portions to be detected, the extent of the area and the distance of the instrument from the remains, while the settings of the quality remained unchanged.

In fact, as regards the scans carried out in proximity of the structures, it was preferred to use a reduced resolution setting compared to the larger acquisitions, for which a higher resolution was chosen due to the greater distance to be covered between the instrument and the objects to be detected.

Parallelly to the acquisition of dimensional data, we proceeded with the recording of high-definition images using a full-frame ${ }^{4}$ reflex camera and related lenses ${ }^{5}$. These images were acquired for two distinct purposes, the first for the creation of a textured three-dimensional model to be obtained thanks to image based photogrammetric elaborations and structure from motion techniques, the latter for the realization of interactive spherical images for the virtual fruition of the archaeological site

Since the two purposes are very different, especially from the point of view of execution and post-production, it was necessary to acquire photographic data in two ways and in two completely different phases.

To take full advantage of the three-dimensional photogrammetric system potentialities, several images were taken in order to completely cover the surface being analysed, including any dark areas or those that are not easily visible. The images were acquired by placing the photographic camera perpendicularly, with an incidence of about $30^{\circ}$ and about $60^{\circ}$ respect to the surfaces of the remains and moving parallelly to these, taking pictures with an overlap of at least $30 \%$ one from

${ }^{4}$ Nikon D600: CMOS sensor 35,9 x 24,0 mm (FX format), picture area $6016 \times 4016$ pixels, 12 or 14 bit NEF memorisation, $100-6400$ ISO, 39 autofocus points.

${ }^{5}$ Nikkor AF-S $50 \mathrm{~mm}$ F/1.8 G and Nikkor AF-S 18-35 mm F/3.5-4.5 G ED. 
the other, horizontally and vertically and turning around any protrusions.

The photos were saved in .NEF format, at the highest possible resolution; the lower ISO value was chosen according to the lighting conditions and an aperture such as to make the whole scene appears completely in focus, reducing to a minimum level the chromatic aberration. For these reasons all shots were made with a $20 \mathrm{~mm}$ focal length and with an aperture between F11 and F13, variable time shoot depending on the illumination and sensitivity of the sensor, set between 200 and 400 .

For the realization of spherical panoramic images, the same photographic instrumentation was used, identifying different points from which to perform the shoots necessary for the composition of the spherical images, so as to obtain very detailed and high-quality elaborations.

On the tripod, previously adjusted in a parallel position to the ground, a panoramic photographic head was mounted. This allowed the SLR camera to have better mobility possibilities, required by the conditions of each different shooting station and the need to constantly match the nodal point of the lens with the vertical axis of the tripod. As before, three shots were taken for each frame (figure 6), one manually setting the most appropriate exposure $(0.0)$ indicated by the camera internal exposure meter, and two others with one stop negative and positive exposure compensation (-1.0, underexposed shot and +1.0 , overexposed shot).

This is for two reasons:

- the first, the need to obtain images with the HDR procedure (High Dynamic Range) through the use of three shots at different exposures in the event that the dynamic range of the final images was not convincing in the postproduction phase;

- the second, the possibility to choose the best of the three saved pictures, given the differences in lighting conditions of the sites.
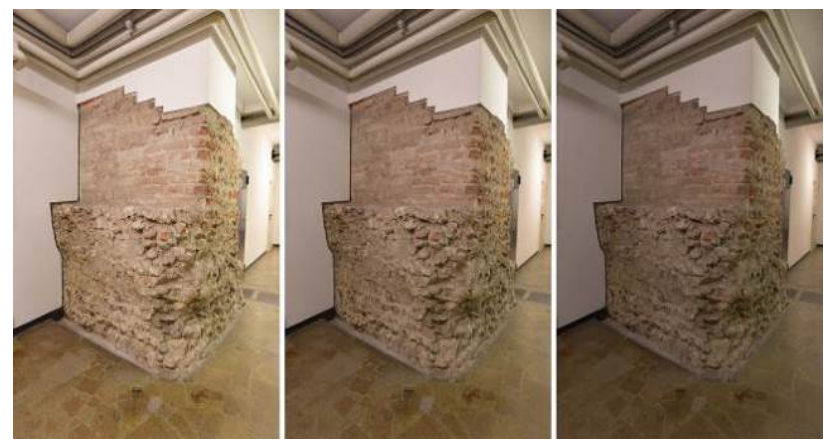

Figure 6. Example of overexposure and underexposure of the same shot, in the middle the image with calibrated exposure

$(0.0)$

During the shoots, the lens was kept at the focal length of about $20 \mathrm{~mm}$ with an aperture of the diaphragm between F8 and F9 to ensure homogeneity between the images.

The photographs were made by rotating the camera on the vertical axis of the tripod so that the next shot covered about $30 \%$ of the previous shoot, first keeping it perfectly parallel to the walking surface (10 shoots), then tilting $35^{\circ}$ on the horizontal axis downwards and $35^{\circ}$ upwards ( 8 shoots for both). The input for each shoot was given to the camera through a wireless control device to avoid any vibrations that could have the risk of getting blurred images. We have tried to have always an overlapping portion between adjacent images to be sure to cover totally the virtual sphere and without empty areas, having as centre the nodal point of the lens, necessary for the correct production of the panorama without parallax errors.

\subsection{Data processing phase}

This phase was initially focused on the processing of data acquired by laser scanner in order to obtain a single point cloud geometrically and chromatically correct and accurate to be used later as a metric basis to align and adapt dimensionally the three-dimensional models obtained through photogrammetric procedures.

The first operations were performed on the separate point clouds, or portions thereof, by applying pre-processing filters. The next phase allowed the identification of the reference points and the assignment of the spatial coordinates deriving from the topographic survey, in order to perform a first alignment with a verification of the errors. Once processed, the individual clouds have been aligned and recorded thus creating a single file containing all the points acquired. Considering that the instrument recorded data up to a distance of about $120 \mathrm{~m}$ from it, it was necessary to remove all unnecessary and redundant points to avoid an excessive weighting of the complete cloud and to improve the general visualization of the threedimensional survey (figure 7). In the final phase of processing, we proceeded applying the photographic images made by the laser scanner to the complete cloud, in order to associate the chromatic data to the spatial information of the single detected points (Russo et al., 2010).

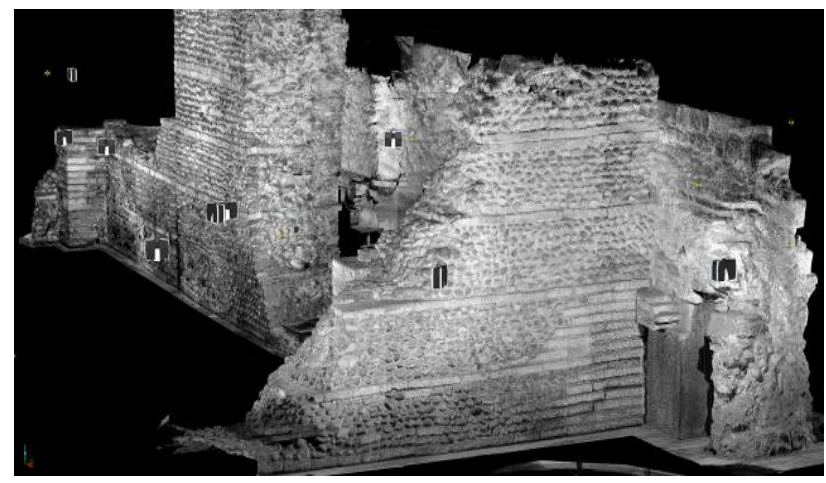

Figure 7. The complete point cloud of the archaeological site in via del Lauro 7

Once the raw data has been processed, the acquired points were verified and the information relating to the colours were applied, it was possible to proceed with the export of the results of the scans in a vectorial environment. For this operation, a specific software was used; this is able to process the recorded points and to project them onto defined planes or on new section planes. The software also allowed to choose the area affected by the projection (from a few millimetres portion to the whole cloud of points), the level of detail and the colour of the points with their intensity (black and white or real colour). To facilitate the identification of the geometric, material and decay/imbalance features of the archaeological remains and to allow exhaustive analyses, it was decided to create sections in plan at different heights and numerous sections in elevation (figure 8).

The large overlap between the photographs allowed the processing software to easily recognize the common points between the images and to permit their alignment by taking advantage of the exif data coming from every single shoot. Once the analysis and alignment phase of the images was completed, it was possible to create a dense cloud of points and 
to define the detailed geometric polygonal model starting from the previous point cloud.

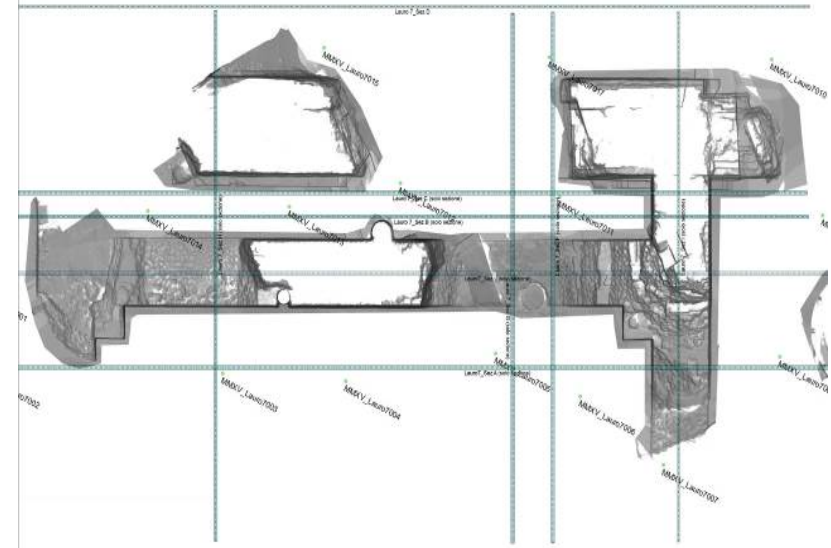

Figure 8. Vertical section plans of the via del Lauro 7 point cloud.

Finally, having verified the correctness of the data processed through dimensional and proportional comparison with the point cloud obtained by laser scanner, first of all it was possible to simplify the polygonal model and then to realize the texture to be applied. This is to be able to export the high-resolution orthoimages of the structures in addition to the threedimensional model itself (Figures 9 and 10; De Luca, 2011).

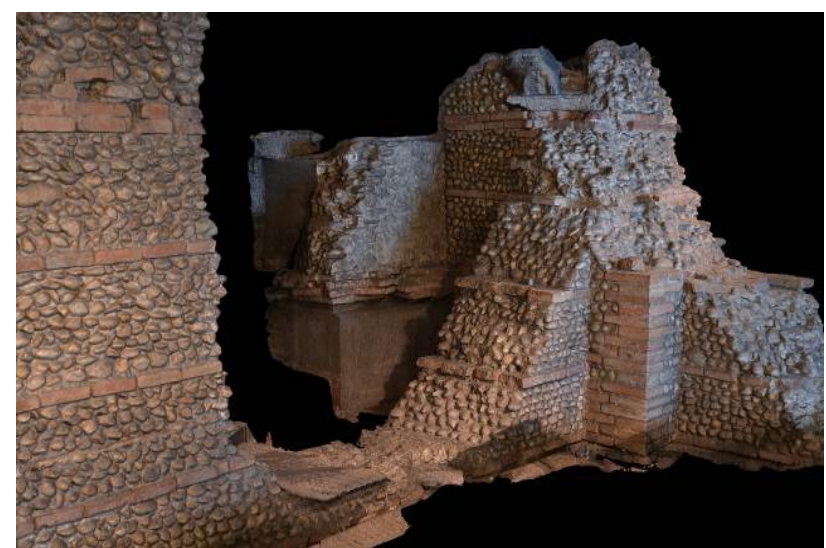

Figure 9. View of the textured three-dimensional model of the via del Lauro 7 archaeological site

Concerning the high resolution interactive panoramic images, procedures similar to the previous ones have been followed for the treatment of basic photographic data. Before proceeding with the final elaboration, panoramic mosaic tests were carried out specifically for the identification of possible parallax errors and problems related to the excessive colour change during the merging of the images.

As before, processing operations were carried out by means of photo-editing software able to allow the modification of the main parameters, levelling out all the shoots.

Subsequently the final mosaic of the images was made; once obtained a preview of the panoramic image, it was possible to check and correct any small inaccuracies resulting from the process. Tests were also carried out with HDR procedures that proved to be satisfactory from a technical-photographic point of view, but certainly not suitable for the type of destination of the works.
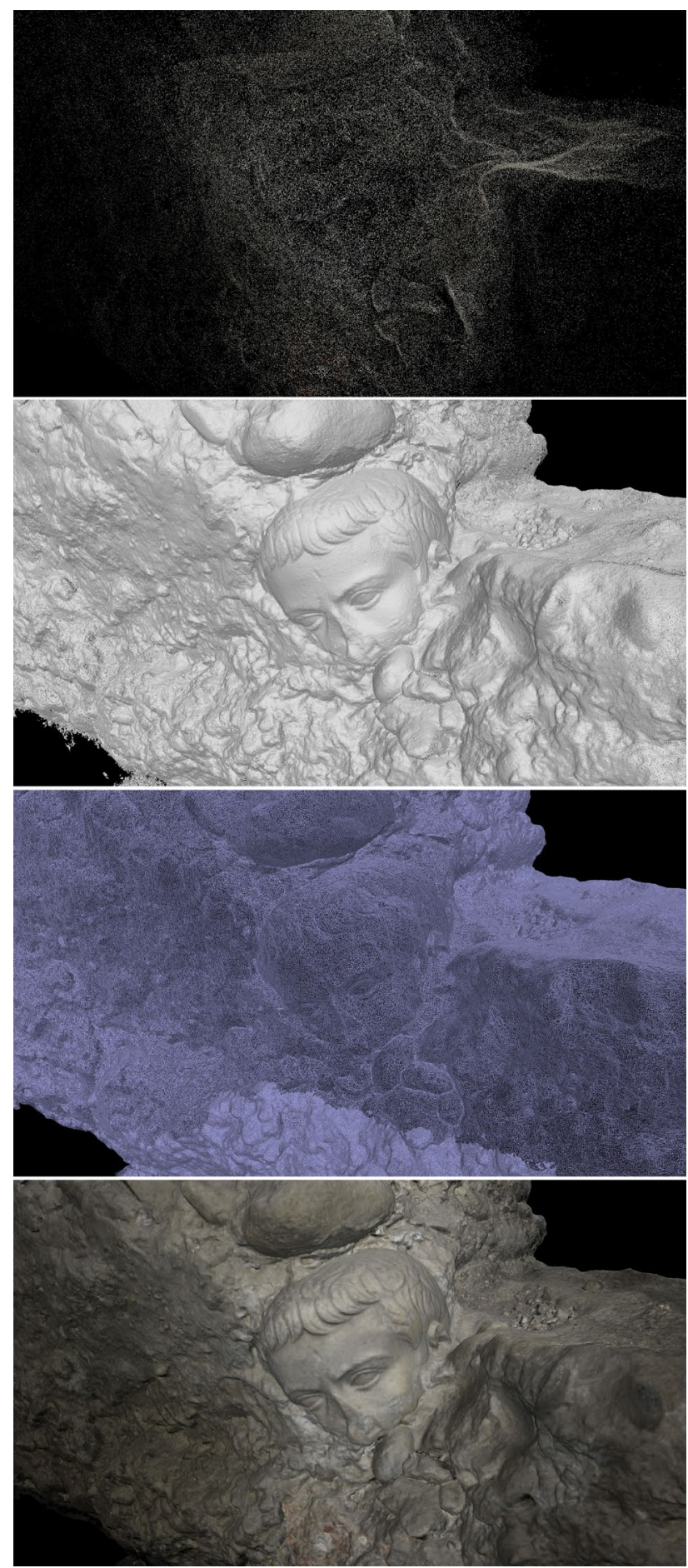

Figure 10. Sequence of the different processing steps for the realization of the high-resolution three-dimensional model of the "Testa di Tiberio" found in the archaeological site under the Church of Santa Maria alla Fonte in via Chiesa Rossa 55.

Finally, a third and final phase allowed the spherical images obtained (figure 11) to be interactive, thus creating a palimpsest of all the archaeological sites investigated. Given the great freedom of this tool, in addition to provide an overall view of the remains of ancient Milan, it will permit, in the future, to be implemented with new sites and information for a clearer and immediate usability. 


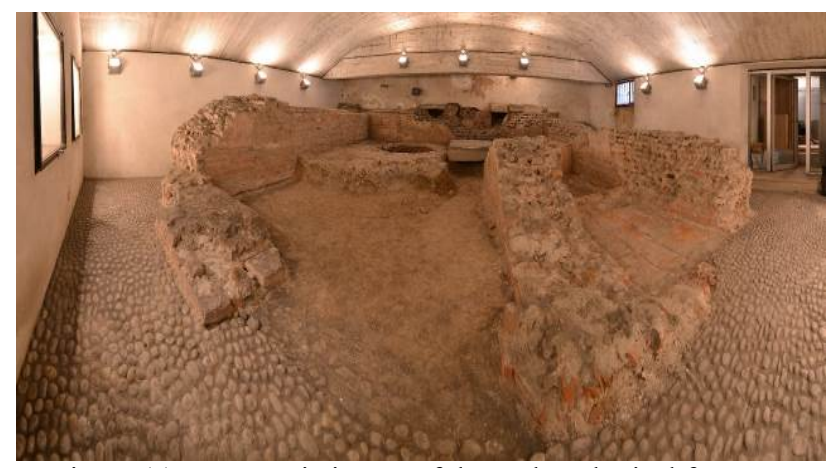

Figure 11. Panoramic image of the archaeological funerary structure in via Santa Valeria 3

\section{CONCLUSIONS}

As part of the "Mediolanum MMXV" project, the documentation activities constituted the necessary actions to define and understand the history of the artefacts, their peculiar characteristics and the state of conservation of the sites.

The results were obtained by the elaboration of multiple data, gradually refined and followed by some operations of knowledge, analysis and study. These led to the representation of all the information deemed useful for the purpose of documentation and communication of archaeological structures. Within the research project, the documentation activities carried out were mainly focused on the acquisition of geometric, morphological and material information in order to provide valid support bases for all the processes of study, analysis and conservation design, on which the components of the research group, belonging to numerous disciplinary fields, were working on (Micoli et al., 2017).

Given the complexity of the sites and their geometric, material and archaeological features, the adopted combination of survey methodologies, including laser scanning, photogrammetric processing and high-definition interactive images, showed to be appropriate for recording the information and characteristics proper to archaeological artefacts, data that are difficult to acquire and to process with the typical two-dimensional survey and representation techniques.

The heterogeneity of the data obtained from the surveys and further processing activities, allowed to use different methodologies of restitution as tools of knowledge and valorisation, which proved to be a valid help for the operators and a concrete system for the enhancement of the places, above all for those inserted inside private properties, not easily accessible or not open to visitors.

\section{ACKNOWLEDGEMENTS}

We would like to thank all the partners of the Mediolanum MMXV research project, with a special mention for prof. Susanna Bortolotto (Politecnico di Milano), prof. Luca Peyronel (Università degli Studi di Milano), Anna Maria Fedeli (Soprintendenza Archeologia, Belle Arti e Paesaggio per la Città Metropolitana di Milano), Carlo Capponi (Arcidiocesi di Milano), Monica Abbiati (Regione Lombardia), Donatella Caporusso e Anna Provenzali (Comune di Milano - Civico Museo Archeologico) that supported us in developing the activities.

\section{REFERENCES}

Abbiati, M., and Fedeli, A.M., 2014. Nascita e sviluppo del progetto. In: Lanx, Vol. 19, Milano, Italy, pp. 13-22.

Barber, D. M., Dallas, R. W., Mills, J. P., 2006. Laser scanning for architectural conservation. In: Journal of Architectural Conservation, Vol. 12(1), pp. 35-52.

Bartoli, L.M., 2002. Conoscenza e rappresentazione, Firenze, Italy.

Bertocci, S., Bini, M., 2012. Manuale di rilievo architettonico e urbano, Milano, Italy.

Bezoari, G., Monti, C., Selvini, A., 2005. Misura e rappresentazione, Milano, Italy.

Bonacchi, C., 2009. Archeologia pubblica in Italia. Origini e prospettive di un 'nuovo' settore disciplinare. In: Ricerche Storiche, Vol. 2-3, Roma, Italy, pp. 329-350.

Bonacini, E., 2011. Nuove tecnologie per la fruizione e valorizzazione del patrimonio culturale, Roma, Italy.

Crosilla, F., Dequal, S. (edited by), 2008. Laser scanning terrestre, Udine, Italy.

De Luca, L., 2011. La fotomodellazione architettonica. Rilievo, modellazione, rappresentazione di edifici a partire da fotografie, Palermo, Italy.

Fedeli, A.M. (edited by), 2015. Milano Archeologia. I luoghi di Milano antica, Milano, Italy.

Fedeli, A.M., Bortolotto, S., Sannazaro, M., De Francesco, S., Ghedini, F., Slavazzi, F., Cecchi, R. and Gasparoli, P., 2014. Tavola rotonda. In: Lanx Vol. 19, Milano, Italy, pp. 204-210.

Ferrara, C., 2007. La comunicazione dei beni culturali. Il progetto dell'identità visiva di musei, siti archeologici, luoghi della cultura, Milano, Italy.

Filippi, F. (edited by), 2004. Manuale per la qualità dei siti Web pubblici culturali, http://www.minervaeurope.org/publications/ qualitycriteria-i/qualitycriteria-i0402.pdf

Garzulino, A., 2016. Il rilievo architettonico: metodologie, tecniche e criticità. In: La manifattura di Legnano. Storie e progetti di riuso, Milano, Italy, pp. 72-74.

Gonizzi Barsanti, S., Remondino, F., Visintini, D., 2012. Photogrammetry and Laser Scanning for archaeological site 3D modeling - Some critical issues. In: 2nd Workshop on 'The New Technologies for Aquileia'. Aquileia, Italy.

Guidi, G., Remondino, F., Russo, M., Menna, F., Rizzi, A., Ercoli, S., 2009. A multi-resolution methodology for the 3D modeling of large and complex archaeological areas. In: International Journal of Architectural Computing, Vol. 7(1), pp. $40-55$.

Guidi, G., Russo, M., 2011. Diachronic 3D reconstruction for lost Cultural Heritage. In: Int. Arch. Photogramm. Remote Sens. Spatial Inf. Sci., Vol. XXXVIII-5/W16, Trento, Italy, pp. 371376. 
ICOM Italia, 2014. Musei e paesaggi culturali, La Carta di Siena.

Melotti, M., 2013. Il ruolo emergente dell'edutainment nella fruizione del patrimonio culturale. In: Formazione\&Insegnamento, Vol. XI(2), pp. 129-142.

Micoli, L.L., Guidi, G., Angheleddu, D., Russo, M., 2013. A multidisciplinary approach to 3D survey and reconstruction of historical buildings. In: 2013 Digital Heritage International Congress (DigitalHeritage). USA, pp. 241-248.

Micoli, L.L., Gonizzi Barsanti, S., Guidi, G., 2017. Interdisciplinary data fusion for diachronic $3 \mathrm{~d}$ reconstruction of historic sites. In: Int. Arch. Photogramm. Remote Sens. Spatial Inf. Sci., Vol. XLII-2/W3, pp. 489-494, https://doi.org/10.5194/ isprs-archives-XLII-2-W3-489-2017.

Okamura, K., and Matsuda, A., 2011. New Perspectives in Global Public Archaeology, New York, USA.

Russo, M., Beraldin, J.A., Guidi, G., 2010. Acquisizione 3D e modellazione poligonale, Milano, Italy.

Skeates, R., McDavid, C., and Carman, J. (edited by), 2012. The Oxford Handbook of Public Archaeology, Oxford, UK.

Volpe, G., and De Felice, G., 2014. Comunicazione e progetto culturale, archeologia e società. In: European Journal of PostClassical Archaeologies, Vol. 4, pp. 401-420. 